\title{
Introducing Constructivism to Young Learners: Analysing the Impact on English Language Performance
}

\author{
Matthew Rudd \\ English Language Centre, Mahanakorn University of Technology, Bangkok 10530, Thailand
}

\begin{abstract}
The significance of this study was to observe the instructional effect of constructivist teaching methodologies on English language performance outcomes among grade four students at a private all-boys school in central Bangkok. The experiment comprised two classes of differing ability: Class One $(n=18)$ classified as above average; and, Class Two $(n=15)$ below average. Both groups were taught according to the traditional Thai syllabus in the first semester of the academic year of 2016/17, transitioning to a constructivist learning environment in the second semester. The results of formal academic assessments were analysed via t-tests $(<0.05)$; and the findings revealed that, as a result of the constructivist program, a significant difference was observed in both classes in relation to speaking attainments. However, in terms of overall language performance, a significant difference was noted in Class One only.
\end{abstract}

Key Words: constructivism, instruction, performance, macro skills, young learners

DOI: $10.7176 / \mathrm{JCSD} / 46-07$

Publication date:March $31^{\text {st }} 2019$

\section{Introduction}

At the 2012 regional high-level expert meeting in Bangkok, organised by UNESCO (Towards EFA 2015 and Beyond - Shaping a New Vision of Education), Dr. Nipon Poapongsakorn, a labour expert at the Thai Development and Research Institute, underlined the major difficulties reported by employers in hiring new (Thai) staff in possession of sound problem-solving skills and work habits. He also questioned why schools fail to produce quality education and skills required for the labour market, subsequently recommending reforms in school curriculums and the introduction of work-based learning programmes.

In Thailand, the curriculum is still heavily based on the memorisation of facts as opposed to reapplying knowledge in unfamiliar contexts, analysing multiple perspectives, reasoning opinions and creative expression through speech and writing. Students are invariably assessed by means of endless multiple choice questions across all subjects in the curriculum, relying on memory recall. Should children be presented with cognitively demanding tasks that encouraged ownership over their learning, they would be provided with opportunities to cultivate their deliberative ability to make reasoned decisions, develop action plans, and use evaluative skills to become responsible forward-thinking adults in the future; as summarised by Dewey (1987), "to prepare him for the future life means to give him command of himself; it means so to train him that he will have the full and ready use of all his capacities". John Dewey, the 93rd most cited psychologist of the $20^{\text {th }}$ century (Review of General Psychology, 2002), had long argued that the major flaw in traditional education is that knowledge is transmitted in one direction, stifling individual autonomy (Dewey, 1904).

Dewey proposed that students thrive in an environment where they are able to experience and interact with the curriculum, and that all students should have the opportunity to take part in their own learning. Dewey's ideas centred on a "hands-on" educational ideology that adequately balances delivering knowledge, while also taking into consideration the practical interests and experiences of the learner. This constructivist ideology was suggested as an alternative to the one-size-fits-all approach that moves students away from conventional schooling and systematic reinforcement to a collaborative learning culture in which students cooperate, share ideas and use critical thinking to solve problems, and come to their own conclusions. Dewey's ideas have influenced the development of many other innovative experiential learning models such as Problem-Based Learning (PBL), a method used widely in education today that integrates Dewey's theoretical framework related to learning through active inquiry (Savery, 2006).

Dewey's growing concern was that the very concept of education was evolving into a formality, failing to educate students how to interpret and analyse concepts, and arrive at social truths through critical and intersubjective discourse. In this regard, Dewey (1902, p. 16) stated "The child and the curriculum are simply two limits which define a single process. Just as two points define a straight line, so the present standpoint of the child and the facts and truths of studies define instruction". He advocated that education and schooling are influential in creating social change and reform, stating that "education is a regulation of the process of coming 
to share in the social consciousness"; and that "the adjustment of individual activity on the basis of this social consciousness is the only sure method of social reconstruction", (My pedagogic creed, Dewey, 1897).

Dewey's proposed constructivist method underlined the necessity to move educators away from a teachercentred system to a child-centred approach; "we must take our stand with the child and our departure from him. It is he and not the subject-matter which determines both quality and quantity of learning", (Dewey, 1902). A number of educators have come to make the distinction between teachers and instructors. Whereas teachers lecture on a given subject-matter, instructors help the learner develop reasoned understanding and analyse outcomes (Bauersfeld, 1995). Instructors, also known as facilitators, move away from the traditional role of a teacher, no longer subjecting learners to play a passive role in the learning process as mere recipients of content. Instructors, however, encourage the learner to play an active and experimental role and place more responsibility on the individual in the learning process; turning the emphasis away from the instructor and the content, and towards the learner (Gamoran, Secada, \& Marrett, 1998).

Teachers mostly lecture in monologue from the front, while facilitators are in constant dialogue with classroom participants, asking a continuum of thought-provoking questions. Teachers answer according to a set curriculum, whereas a facilitator provides a learning environment for learners to arrive at their own conclusions (Rhodes \& Bellamy, 1999). Constructivists have long since deemed traditional teachers as dictators of content; "The core of the constructivist philosophy is that knowledge is not given, but gained through real experiences that have purpose and meaning to the learner" (Piaget \& Inhelder, 1969).

Educators are expected to possess an innate sense of dedication and enthusiasm to share knowledge with others, continually deepen their own knowledge in their respective subject areas, implement and reflect on teaching methods, and, to inquire into other social issues related to the profession (Dewey, 1904, p. 15); these are itemised principles that should "work automatically, unconsciously" (Dewey, 1904, p. 18). Dewey believed that the root of social reform stems from the classroom, and that "the business of the teacher is to produce a higher standard of intelligence in the community ... to help in producing the many kinds of skill needed in contemporary life" (Dewey, 2010). The same source quotes Dewey as allocating the cause of the Great Depression to a consequence of "lack of sufficient production of intelligence, skill, and character" (p. 242).

\subsection{Criticisms of Constructivism}

The central criticism against constructivism is the accusation that the framework is too undefined; "To us it would appear that constructivism remains more of a philosophical framework than a theory that either allows us to precisely describe instruction or prescribe design strategies" (Tobias \& Duffy, 2009). Mayer (2004) also questioned the structural context suggesting more concrete guidelines and teacher involvement; "Yet a dispassionate review of the relevant research literature shows that discovery-based practice is not as effective as guided discovery". This conclusion was based on the reviews of literature spanning over three decades (1960's, 1970's and 1980's). Based on these findings he proclaimed that "constructivism = hands-on activity is a formula for disaster"; subsequently coining the term constructivist teaching fallacy (cited from American Psychologist, 2004, p.14-19).

Sweller et al. (2012) also found that pure discovery was not appropriate for novices, as "direct, explicit instruction is more effective and more efficient than partial guidance". He also added that often only the brightest students make the discovery, and that novice students respond more effectively to worked examples, gradually fading the level of guidance as students gain mastery. These criticisms, however, may be a product of individual misinterpretation, thus leading to poor implementation. Millar (1989) ripostes "what experts already know, determines what they see and how they see it. "Because novices know little about a subject or a domain, they do not know where to look and, having looked at something, have trouble correctly interpreting what they see"; also adding, "(Subjects) should be taught in whatever way is most likely to engage the active involvement of learners, as this is most likely to make them feel willing to take on the serious intellectual work of reconstructing meaning....".

\section{Review of related studies}

The theoretical framework of constructivism studied in this section is fundamentally based on the concept of Montessori style education, which embraces open-concept arrangement of desks resembling a formation of rafts to encourage group work and peer collaboration. Students' age categories range across a three year grade as opposed to a single year grade (Chatting-McNichols, 1992), and students usually spend three to four hours on 
self-selected work projects each day, performed individually or in small groups. Direct instruction is typically limited to no more than one hour per day (Baines \& Snortum, 1973).

\subsection{Montessori Research in the USA}

A data-driven Montessori related study conducted by the State University of New York appeared in the Journal of Research in Childhood Education (2005, Vol.20, No.1), and compared students' academic achievements in maths and language arts across a sample size of 543 urban $4^{\text {th }}(n=291)$ and $8^{\text {th }}(n=252)$ grade students from four separate institutions; mostly from low-income (67\%) and ethnic backgrounds (53\%). The results from those who attended Montessori education $(n=88)$ were compared with those from Structured Magnet Programmes $(n=114)$, Open Magnet $(n=175)$ as well as Traditional Non-Magnet $(n=166)$. The results were largely unfavourable and failed to support the hypothesis that enrolment in a Montessori school was associated with higher academic performance.

A further Montessori related study appeared in the scientific journal Science (Sept. 29, 2006), which focused on an urban minority of children (Milwaukee USA), carried out by Angeline Lillard, a University of Virginia professor of psychology. Her strategy was to randomly sort applicants for enrolment into two groups. The students accepted on to the programme were allocated to study group A, whereas study group B consisted of unsuccessful applicants who were subsequently placed in schools and taught conventionally. Students in each learning environment were tested in two age groups; ages 3-6 and 6-12.

The criteria involved testing for cognitive and academic skills, and also for social and behavioural skills. For group A, the Montessori school, "We found significant advantages for the Montessori students in these tests for both age groups,". Lillard observed "Particularly remarkable are the positive social effects of Montessori education". Allegedly, the study found that Montessori students at age 5 proved to be significantly more prepared for elementary school in terms of reading and mathematics skills, compared to the non-Montessori children. In addition, the same paper claimed that among the 12-year-olds from each group, the Montessori students produced essays that were rated as "significantly more creative and as using significantly more sophisticated sentence structures".

Interestingly, the Montessori and non-Montessori students were operating on an even par with regards to spelling, punctuation, grammar, and mathematics. This comparable level of academic attainment could be partly due to the fact that Montessori children are not accustomed to regular tests and grade systems. Furthermore, the profile of the participants (minority students) in both studies lacked clarity in terms of ethnic profiles and details of socio-economic status.

\subsection{Montessori research in Thailand}

Through courtesy of the Montessori website, details were provided on a study that was carried out in Khong Kaen during the first semester of the 2010 academic year, involving 600 kindergarten children aged 5 years old; 300 of which were following the Montessori approach, and 300 were subject to traditional forms of education. The results concerning language development apparently revealed that Montessori children were able to write the names corresponding to the correct image with the highest score of $7-8$ words $(78.3 \%)$; moreover, every child demonstrated literacy capabilities. This score is significantly higher when compared to the children who had been learning in a traditional environment; among this group $40.3 \%$ scored at 1-2 words. Furthermore, 33 children from this programme, (11\%), were proven to be illiterate.

The study therefore concluded that the overall intellectual performance and language skills of Montessori children proved to be significantly superior. However, the unfairness of the test was that the participants in the Montessori study in Kong Kaen were already accustomed to a constructivist learning environment. Moreover, it remains unclear whether the students were assessed on their Thai or English language skills.

\subsection{The significance of this study}

The studies reviewed above were not experiential in nature and did not test the teaching practices of constructivism, but rather focused on the collation of results and test scores. The significance of this paper is to test the observable instructional impact of constructivism on young learners' English language performance; contrasting the results of the constructivist program with those previously attained under a traditional style of education. 


\subsection{Research questions}

1. What is the current level of English language performance of both groups prior to the constructivist programme?

2. As a result of the constructivist programme, is there a significant difference in students' English language performance in terms of (1) overall grade, and, (2) individual macro skills development?

\subsection{Null hypotheses}

1. There is no significant difference in the overall English language performance of both groups as a result of constructivism.

2. As a result of constructivism, there is no significant difference in English language performance in relation to individual macro skills development.

\section{Methodology}

The participants in this sample comprised 2 groups of prathom 4 (grade four) students of differing ability who were studying on an Intense English Program at a well-known private all-boys school in central Bangkok. Class One $(n=18)$ consisted of students whose academic ability was classified as above average, and Class Two $(n=$ 15) consisted of students whose abilities were deemed below average.

During the first semester, the grade four participants underwent a traditional style of English language instruction; subsequently transitioning to a problem-based constructivist style learning programme in the second semester. The independent variable constituted the change in learning environment, and the controlled variables comprised the participants, the criteria of assessment and the teacher; which all remained unchanged throughout the trial. The sole categorical variable was the classification of students according to ability, in that Class One was regarded as above average, and Class Two below. Thus, the dependent variable consisted of the observable variation in students' English language performance outcomes across all four macro skills at the end of both semesters.

The first semester of traditional style schooling mainly consisted of coverage-based learning, which generally relied on text books, listening exercises, grammar drills and worksheets. In the second semester, inspired by the Montessori programme, students moved from sitting in rows facing the teacher to sitting in groups, or "rafts", where they worked collaboratively with peers to solve problems, create role plays in line with scenario-based learning, express opinions on presented material, and collaboratively develop projects. The teacher moved from providing instructional knowledge to facilitating ideas and assisting students' participation in discovery-based learning; in keeping with Piaget's ideology that children developed their cognitive ability through interaction with the environment and learning collaboratively with peers - discovery learning (Woolfolk, 2004).

Overall grades for language performance were recorded as a percentage, and the value of which is represented by a single letter grade. However, all individual forms of macro skills assessment were graded out of 20 and converted accordingly:

Table 1: Scores conversion chart

\begin{tabular}{|c|c|}
\hline Score & Grade \\
\hline $18+$ & $90 \%=\mathrm{A}+$ \\
\hline 16 & $80 \%=\mathrm{A}$ \\
\hline 14 & $70 \%=\mathrm{B}$ \\
\hline 12 & $60 \%=\mathrm{C}$ \\
\hline 10 & $50 \%=\mathrm{D}$ \\
\hline$<9$ & $<49 \%=\mathrm{F}$ \\
\hline
\end{tabular}




\subsection{Data analysis}

The test results across both semesters (traditional and constructivist teaching) were compared via a t-test for significance testing $(<0.05)$ to determine the impact of constructivism on both groups. Within this parameter, five separate t-tests were conducted; firstly, to cross-examine the overall English language performance variations at the end of both semesters; and secondly, (four) itemised t-tests to were carried out to identify students' performance variations across individual macro skills (speaking, writing, reading and listening).

\section{Findings/Results}

The first question was to ascertain the students' current level of English at the end of term one, and, the subsequent impact of constructivist teaching at the end of term two.

Table 2: difference in students' overall English language performance

\begin{tabular}{|l|c|c|c|c|c|}
\hline CLASS ONE & M & SD & T & CR & Result \\
\hline Traditional & $77.77 \%(\mathrm{~B})$ & & & & \\
\hline (term one) & & & & & \\
\hline & & 5.356 & 2.2674 & 2.032 & Sig \\
\hline Constructivist & $82.27 \%(\mathrm{~A})$ & & & & $>0.5$ \\
\hline (term two) & & & & & \\
\hline CLASS TWO & M & SD & T & CR & Result \\
\hline Traditional & $58.66 \%(\mathrm{D})$ & & & & \\
\hline (term one) & & & & & Not Sig \\
\hline & & 8.432 & 0.7441 & 2.048 & $<0.5$ \\
\hline Constructivist & $60.53 \%(\mathrm{C})$ & & & & \\
\hline (term two) & & & & & \\
\hline
\end{tabular}

In response to the first research question, Table 2 shows that prior to commencing the constructivist program, the students' language performance was classified as follows; Class One (M: 77.77\%; grade B, above average), and that of Class Two (M: 58.66\%; grade D, below average). Moreover, the standard deviation in class two was greater, inferring that grade outcomes varied on a larger scale in the lower-level class. As noted in Table 2, the difference in students' academic performance attainment as a result of constructivist teaching produced two disparate outcomes. Class One's response to constructivism resulted in significant improvements in English language attainments, as the value of $\mathrm{T}$ exceeded the critical value, $(2.2674>2.032)$; suggesting that both means were significantly different; thus constructivism significantly contributed to enhancing student performance. However, with regards to Class Two, there was no significant response to constructivism despite the rise in average grade (from D to C). Statistically, the absolute value of the calculated T remained inferior to the critical value, $(0.7441<2.048)$, thus the means were not considered to be significantly different. This is largely owed to the fact that only a select few students showed signs of noteworthy progress, (4 students out of 15$)$; which also explains the higher levels of standard deviation. 
The second research question was to examine the potential development of macro skills as a result of constructivism:

Table 3: Difference in Students' macro skills performance: Class One

\begin{tabular}{|l|l|l|r|r|l|}
\hline \multicolumn{1}{|c|}{ Macro } & \multicolumn{1}{c|}{ M: Trad. } & M: Const. & \multicolumn{1}{c|}{ T } & \multicolumn{1}{c|}{ CR } & \multicolumn{1}{c|}{ Result } \\
\hline Speaking & $14.389(\mathrm{~B})$ & $17.556(\mathrm{~A})$ & 4.34 & 2.032 & $>0.5 \mathrm{Sig}$ \\
\hline Writing & $15.889(\mathrm{~B})$ & $17.333(\mathrm{~A})$ & 1.77 & 2.032 & $<0.5$ Not sig \\
\hline Reading & $15.889(\mathrm{~B})$ & $15.611(\mathrm{~B})$ & 0.37 & 2.032 & $<0.5$ Not sig \\
\hline Listening & $15.722(\mathrm{~B})$ & $15.389(\mathrm{~B})$ & 0.48 & 2.032 & $<0.5$ Not sig \\
\hline
\end{tabular}

Table 3 reveals that after the second semester of constructivist teaching, speaking skills improved significantly in Class One, given the value of T (4.35) is superior compared to the respective critical value (2.023). However, the results for writing $(1.77<2.032)$, reading $(0.37<2.032)$ and listening $(0.48<2.032)$ failed to show significant signs of progress, as these corresponding $\mathrm{T}$ values remained inferior to the critical value.

Table 4: Difference in Students’ Macro Skills Performance: Class Two

\begin{tabular}{|c|c|c|c|c|c|}
\hline Macro & M: Trad. & M: Const. & $\mathbf{T}$ & CR & Result \\
\hline Speaking & 11.33 (D) & 13.33 (C) & 4.83 & 2.048 & $>0.5 \mathrm{Sig}$ \\
\hline Writing & 11 (D) & 11.46 (D) & 1.45 & 2.048 & $<0.5$ Not sig \\
\hline Reading & $11.33(\mathrm{D})$ & 11.06 (D) & 1.29 & 2.048 & $<0.5$ Not sig \\
\hline Listening & $12 \quad(\mathrm{C})$ & $11.6 \quad$ (D) & 1.25 & 2.048 & $<0.5$ Not sig \\
\hline
\end{tabular}

In concert with the previous group, the data presented in Table 4 for Class Two displays a similar trend in that speaking skills improved significantly among the academically challenged group, as the $\mathrm{T}$ value exceeded the critical threshold $(4.83>2.048)$, nonetheless, the $\mathrm{T}$ value for all other macro skills remained inferior to the critical value; writing $(1.45<2.048)$, reading $(1.29<2.048)$ and listening $(1.25<2.048)$.

\subsection{Further discussion}

From the results analysed, there are three central aspects highlighted for further discussion; the effects of constructivism, reflections on the respective implementation, the limitations of this study, and potential scope for further research.

\section{The effect of constructivism on English language development}

The reasons accounting for the marked underperformance in passive macro skill areas may have been owed to the nature of constructivism, seeing that activities emphatically focused on speaking and creative tasks, and decidedly less so on reading comprehension and listening practice; as reflected in the results. In the case of this trial, the level of success seemingly depended on the students' natural academic potential, as the more academically able group responded more positively to a constructivist setting, whereas, the below average class failed to replicate this level of progress. These findings directly relate to Sweller et al.'s assertion (2012) that constructivism was not productive for novices, and that the discovery is often missed. Sweller (1985) suggests that individuals learn by studied examples, known as the worked-example effect, transitioning to a more autonomous learning environment when developmentally appropriate (guidance-fading effect). As a result, following Sweller's suggestions of increasing the level of guidance for less capable students seems to constitute a valid proposal in this context. This paper followed the Montessori programme working on the basis of 1 hour of directed instruction to every 4 hours of discovery-based learning, and evidently, one size appears not to fit all. 


\section{Further reflections on the implementation of constructivism}

A greater degree of standard deviation in the second class would suggest that grade outcomes varied particularly more in this lower level group, and, that a small number of highly skilled students were present in the classroom. One possible solution could consist of sorting groups to include multiple (and evenly distributed) tiers of ability: below average, average and above average. In accordance with the More Knowledgeable Other theory (Vygotsky 1978), this may produce a more mutually beneficial collaborative effect, as more skilled learners can work with struggling peers to solve problems, cooperating to solve problems through collaborative dialogue. Furthermore, a number of the more academically challenged students had specialist learning requirements, and, disruptive behaviour was also a hindrance to the introduction of certain discovery-related activities. Therefore the presence of a Thai teacher in the classroom may soothe the transition into constructivism to (1) manage potential disciplinary issues, and (2) to reinforce understanding of novel tasks, supported by (3) closer parental collaboration to resolve specific learning needs and cases involving undue behaviour.

\section{Limitations of the study and suggestions for further research}

This experiment exclusively comprised grade four students aged between nine and ten years. At this age, learners are still in the concrete operational stage (ages 7-11), in which they can solve problems that apply to actual concrete objects or events; but, are unable to resolve abstract concepts, hypothetical tasks or apply deductive knowledge (Santrock, 2008). The full extent of common sense, inclusive of both inductive and deductive logic, hypothesising, and the understanding of multi-perspective viewpoints does not become active until the formal operational stage, typically aged 11 onwards (Piaget, 1972). In response to this, one particular recommendation would therefore constitute expanding the scope of research to also include older learners. Moreover, the findings reported in this paper derived from two separate grade four classes from one all-boys private school located in the Thai capital. To enlarge the scope of research more extensively, the inclusion of a range of schools representing various socio-economic profiles in both urban and rural areas merits consideration.

\section{Conclusions}

As a result of constructivism, speaking skills improved considerably across both groups; whereas writing, reading and listening skills failed to improve, if not deteriorated. As a result, these findings failed to disprove Mayer's conceptualisation of the constructivist fallacy. Based on the observation that constructivism did assist in the development of communicative skills, suggesting an amalgamation of constructivism with certain constructs of traditional education would perhaps prove to be more optimal at this level. Extension tasks could be added to conventional listening exercises, grammar drills and reading comprehension in order to enhance both active and passive macro skills concomitantly. Mastery of active skills and encouraging innovative contributions to the classroom may also begin to address the shortfall in key work-related skills required for future life, which inevitably centre on strong communication skills, individual initiative, and creativity.

\section{References}

1. Baines, M., Snortum, J. (1973). Time-sampling analysis of Montessori versus traditional classroom interaction. The Journal of Educational Research, 66(7): (pp. 313-316).

2. Bauersfeld, H. (1995). The Structuring of the structures: development and Function of Mathematizing as a Social Practice. Proceedings of the conference of alternative epistemologies in education. Constructivism in education; 1992; Athens. (pp.137-158).

3. Chatting-McNichols, J. (1992). The Montessori Controversy, Cengage Learning.

4. Dewey, J. (1897). My Pedagogic Creed. The School Journal, 3: (pp.77-80.).

5. Dewey, J. (1902). The Child and the Curriculum, (pp. 13-14). Chicago: University of Chicago Press.

6. Dewey. J. (1904). The Education Situation. University of Chicago Press.

7. Gamoran, A., Secada, W.G., Marrett, C.B. (1998). The organizational context of teaching. Educational Evaluation and Policy Analysis, 20: (pp. 229-252).

8. Lillard, A. (2017). Montessori: The Science Behind the Genius. New York: Oxford University Press. (pp. 351-376).

9. Mayer, R. (2004). Should there be a three-strikes rule against discovery learning? American Psychologist 59(1): (pp.14-19).

10. Piaget, J. (1972). The Psychology of Intelligence. Routledge Classics. 
11. Piaget, J., Inhelder, B. (1969). The Psychology of the Child. Basic Books, New York.

12. Poapongsakorn, N. (2015). Quality of Thai Workforce: Evidence and linkages between schools and the labour market. Proceedings of the conference of Towards EFA 2015 and Beyond - Shaping a New Vision of Education. UNESCO, Bangkok, Thailand.

13. Rhodes, L. K., Bellamy, T. (1999). Choices and consequences in the renewal of teacher education. Journal of Teacher Education. 50: (pp.17-26).

14. Santrock, J.W. (2010). A topical approach to life span development: (pp.221-222).

15. Savery, J. R. (2006). Overview of problem-based learning: definitions and distinctions. Journal of Problem based Learning, 1(1).

16. Sweller, K., Cooper. G. A. (1985). The use of worked examples as a substitute for problem solving in learning algebra. Cognition and Instruction 2(1): (pp. 59-89).

17. Sweller, J., Clark, R., Kirschner. P. (2012). Putting students on the path to learning: the case for fully guided instruction. American Educator. Spring 2012. (pp. 6-11).

18. Tobias, S., Duffy, T.M. (2009). Constructivist instruction: Success of failure? 